\title{
Dose and dose-rate dependency in the mortality response of Calanus finmarchicus embryos exposed to ultraviolet radiation
}

\author{
Howard I. Browman ${ }^{1,3, *}$, Jean-François St-Pierre ${ }^{1}$, Penelope Kuhn ${ }^{1,2}$ \\ ${ }^{1}$ Department of Fisheries and Oceans Canada, Maurice Lamontagne Institute, PO Box 1000, 850 Route de la Mer, Mont-Joli, \\ Québec G5H 3Z4, Canada \\ ${ }^{2}$ CONFORTE (CONsulting FOR The Environment), 94 Joyce Court, Lake Echo, Nova Scotia B3E 1A8, Canada \\ ${ }^{3}$ Present address: Institute of Marine Research, Austevoll Aquaculture Research Station, 5392 Storebø, Norway
}

\begin{abstract}
In previous work, we reported that embryos of Calanus finmarchicus exposed to artificial ultraviolet-B (UV-B) radiation exhibited high wavelength-dependent mortality. The strongest effects occurred under exposures to wavelengths below $312 \mathrm{~nm}$ and, at the shorter wavelengths $(<305 \mathrm{~nm})$, UV-B-induced mortality was strongly dependent on cumulative exposure (i.e. dose). In the experiments reported here, we tested (for $C$. finmarchicus) the principle of reciprocity - that is, was the effect of cumulative UV dose the same regardless of the dose rate at which it was delivered? Dose rate had no discernible effect on the proportion of live $C$. finmarchicus nauplii recovered from eggs exposed to 3 different UV doses: reciprocity held. The doses and dose rates administered were ecologically relevant. However, the issue of UV dose versus dose-rate effects on marine organisms requires further investigation - at a broad range of dose and dose rates and for different exposure durations, preferably under natural sunlight.
\end{abstract}

KEY WORDS: Calanus finmarchicus $\cdot$ Reciprocity $\cdot$ UV $\cdot$ Dose $\cdot$ Dose rate

Resale or republication not permitted without written consent of the publisher

Female Calanus finmarchicus (a key species in North Atlantic food webs) release their eggs near the surface of the water, probably during the night and early morning (Runge \& Plourde 1996). Thirty to fifty percent of these eggs remain in the top $5 \mathrm{~m}$ (Runge \& Plourde 1996), where, in the Gulf of St. Lawrence, $10 \%$ depths (depth to which $10 \%$ of incoming irradiance penetrates) can reach 3 to $4 \mathrm{~m}$ at $310 \mathrm{~nm}$ (Kuhn et al. 1999) and temperature is approximately $6^{\circ} \mathrm{C}$. In previous work, we reported that embryos of $C$. finmarchicus exposed to artificial ultraviolet-B (UV-B, 280 to $320 \mathrm{~nm}$ ) radiation exhibited high wavelength-dependent mortality (Kouwenberg et al. 1999a). The strongest effects occurred under exposures to wavelengths below $312 \mathrm{~nm}$, and, at the shorter wavelengths $(<305 \mathrm{~nm})$,

*Email: howard.browman@imr.no
UV-B-induced mortality was strongly dependent on cumulative exposure (i.e. dose). A biological weighting function (BWF), characterizing wavelength-specific UV-B-induced mortality in C. finmarchicus eggs, was derived from these data (Kouwenberg et al. 1999a). This BWF has been used to evaluate the susceptibility of C. finmarchicus populations to UV-B exposure under a variety of scenarios, including those predicted for various percent thinnings of the ozone layer (Kuhn et al. 2000, Browman 2003).

One of the more important fundamental assumptions for construction (and application) of accurate dosedependent BWFs is the principle of reciprocity (e.g. DeGruijl et al. 1986, Cullen \& Neale 1997, Kouwenberg et al. 1999a, Grad et al. 2001, Williamson et al. 2001). In the context of a UV-exposure experiment, reciprocity holds when the effect of cumulative dose is the same regardless of the dose rate at which it was delivered. If reciprocity fails, a short intense exposure would result in a different effect than a long weak exposure to the same cumulative dose. In this latter case, evaluations of effect versus cumulative exposure (i.e. dose dependence) cannot be applied outside of the conditions (i.e. time scales) under which they were generated. BWFs derived from such results would be less robust and of more limited use (see Neale et al. 2001, Williamson et al. 2001). Despite its importance, the principle of reciprocity has not often been rigorously evaluated, and when it has the results have been inconsistent (see 'Discussion').

In our original presentation of the BWF for Calanus finmarchicus embryos (Kouwenberg et al. 1999b), we did not evaluate whether UV-B-induced mortality was independent of dose rate under the range of conditions used to generate it. The experiments reported upon here address this issue. 


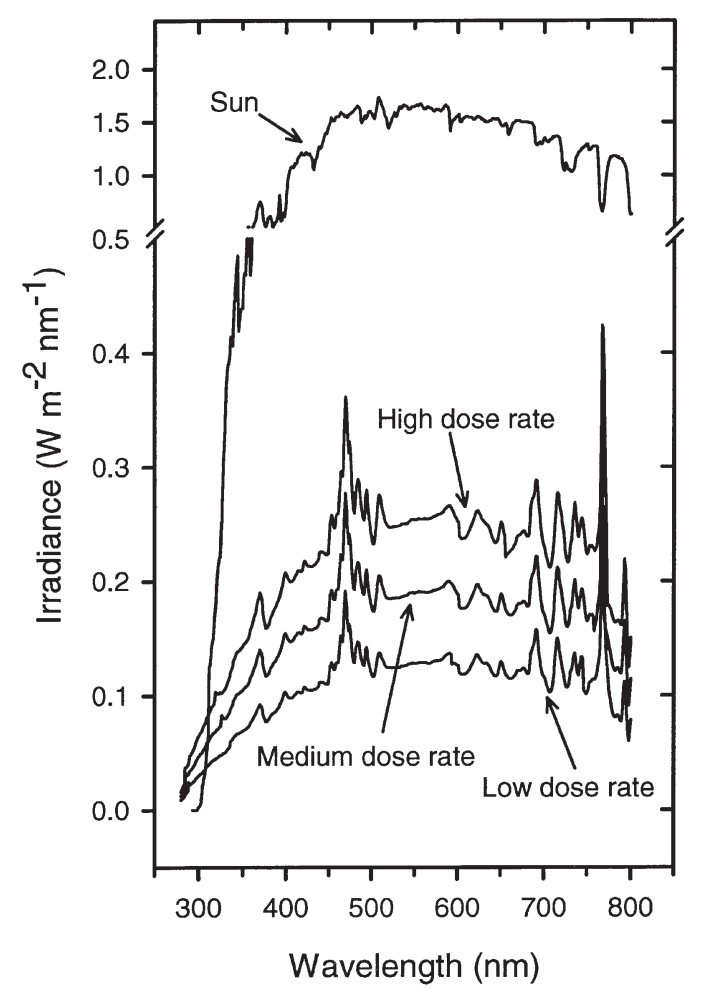

Fig. 1. Spectral irradiance $(280-800 \mathrm{~nm})$ of the low, medium and high dose rates delivered to Calanus finmarchicus eggs in the reciprocity experiments. An example of solar spectral irradiance (terrestrial), measured under cloudless skies on 5 August 1996 at 13:05 h Eastern Daylight Time outside the Maurice-Lamontagne Institute, Mont-Joli, Québec, Canada $\left(48^{\circ} 38^{\prime} 25.9^{\prime \prime} \mathrm{N}, 68^{\circ} 09^{\prime} 21.0^{\prime \prime} \mathrm{W}\right)$, is presented as a reference

Materials and methods. Calanus finmarchicus females were collected mid-August (1998) in the lower St. Lawrence estuary $\left(48^{\circ} 40.10^{\prime} \mathrm{N}, 68^{\circ} 34.40^{\prime} \mathrm{W}\right)$ using a $1 \mathrm{~m}$ diameter plankton net (333 $\mu \mathrm{m}$ mesh size) towed vertically from $250 \mathrm{~m}$ to the surface. The net's contents were transferred to gallon jars filled with filtered seawater $(0.2 \mu \mathrm{m})$ at $6^{\circ} \mathrm{C}$ and transported to the laboratory in coolers. C. finmarchicus females were sorted, placed in 101 tanks, and fed on Skeletonema costatum (at 50000 cells $\mathrm{ml}^{-1}$ ). This strain of $S$. costatum is not harmful to the hatching success of Calanus sp. eggs (Ban et al. 1997). The water in the culture tanks was refreshed daily.

Eggs - released during spawning the previous night were collected between 09:00 and 10:00 h on the day of each experiment. A total of 1000 eggs were counted under a dissecting microscope and distributed (in equal numbers of 50 tube $^{-1}$ ) into 20 quartz tubes. For any given experiment, all of the eggs were the progeny of the same group of females. Tubes were $20 \mathrm{~mm}$ in diameter $\times 10 \mathrm{~cm}$ length and were sealed at the top with an optical filter (see below) and at the bottom with
$73 \mu \mathrm{m}$ mesh Nitex $^{\mathrm{TM}}$. This allowed water to circulate into the tubes throughout, and between, UV-B exposures. Tubes were placed into an incubator filled with recirculating filtered $(0.2 \mu \mathrm{m})$ seawater $(27.5 \pm$ $0.5 \mathrm{PSU})$ at $6.0 \pm 1.0^{\circ} \mathrm{C}$. The incubator $(20 \mathrm{~cm}$ diameter $)$ was positioned so that the tops of the tubes were $1 \mathrm{~m}$ below the collimated downwelling light field produced by a solar simulator (SS). Tubes were submerged in $3 \mathrm{~cm}$ of water. Detailed characteristics of the SS have been published elsewhere (Kouwenberg et al. 1999a).

Each experiment included 3 spectral exposure treatments and a control, with 5 replicates each (Fig. 1). Spectral exposures were generated by covering the quartz tubes with specific long-pass filters: 305 (UV-B), 320 (UV-A), and 400 (visible) nm. The spectral transmission profiles of these filters have been published elsewhere (Kouwenberg et al. 1999a). Control (dark) tubes were wrapped with aluminium foil.

The spectral irradiance (280 to $800 \mathrm{~nm}$, at $1 \mathrm{~nm}$ intervals) delivered by the SS (at the level of the incubation tubes) was measured using a $100 \mathrm{~mm}$ diameter submersible integrating sphere (OL-IS-470-WP, Optronic Laboratories) attached to a scanning spectrophotometer (OL 754-O-PMT) via a $16 \mathrm{~m}$ UV-grade quartz fiber-optic cable. Optronic Laboratories specifies the instrument's stray light rejection to be $10^{-4} \mathrm{~W} \mathrm{~m}^{-2} \mathrm{~nm}^{-1}$ with a spectroradiometric accuracy relative to the US National Institute of Standards (NIST) of $\pm 1-3 \%$. The full-width half-maximum setting was $1 \mathrm{~nm}$. The instrument was calibrated against a NIST-traceable $200 \mathrm{~W}$ tungsten-halogen standard lamp (OL 752-10) before each series of measurements. The wavelength and gain accuracy were also checked (using an OL 752-159 dual calibration and gain check source module with a wavelength accuracy of $\pm 0.1 \mathrm{~nm})$. Since there was some spatial variability in the SS's output, spectral irradiance was measured at 4 locations; these energy fluxes are presented as averages, for the incubator as a whole (Table 1). To minimize the possible effect of spatial variability in the SS's output, the 5 incubation tubes for any 1 spectral exposure treatment were positioned in different locations within the incubator - that is, as a whole, the group of 5 replicates received doses and dose rates as reported in Table 1.

To test whether the UV-B-induced mortality response of Calanus finmarchicus embryos is dose or dose-rate dependent, eggs were incubated under 3 UV-B doses, each delivered at 3 different dose rates (i.e. irradiances). Different doses were achieved by varying exposure times, different dose rates by changing the power output of the SS (Table 1). The dose/ dose-rate combinations were chosen so that (1) the mortality responses would be neither negligible nor total (since C. finmarchicus embryos are highly susceptible to UV-B exposure, this required very short 
incubation times) and (2) they would overlap the spectral irradiance conditions used to generate the BWF previously reported (Kouwenberg et al. 1999b). The energy fluxes required to achieve this were determined from the waveband-specific dose versus mortality relationships presented in Kouwenberg et al. (1999b). Because C. finmarchicus eggs all have similar mass and absorption cross-sectional areas (Runge \& Plourde 1996), the irradiances measured can reasonably be considered as an estimate of dose.

To determine the ecological relevance of the experimental doses and dose rates, the daily UV (290 to $350 \mathrm{~nm}$, the wavelength range over which damage occurs) exposure of Calanus finmarchicus embryos was calculated using a simulation model (Kuhn et al. 2000). The model was developed for water masses in the estuary and Gulf of St. Lawrence, and so is directly relevant, and applicable here. A wide range of conditions were included in this analysis: irradiances from clear and cloudy days, diffuse attenuation coefficients for the water columns ranging from 1 to $6 \mathrm{~m}^{-1}$ (at $290 \mathrm{~nm}$ ) in the Gulf and estuary respectively, mixed layer depths of 10 to $50 \mathrm{~m}$, and surface wind speeds varying between 0 and $10 \mathrm{~m} \mathrm{~s}^{-1}$. For all model simulations, embryo assemblages (200 embryos) were initially distributed uniformly in the top $5 \mathrm{~m}$ of the water column and assigned a sinking rate of $32 \mathrm{~m} \mathrm{~d}^{-1}$ (Marshall \& Orr 1953). Simulations were performed under extant ambient atmospheric ozone levels.

After these one-time exposures under the SS, tubes were emptied into Petri dishes ( $1 \mathrm{~cm}$ deep) which were placed in a temperature-controlled room at $6.0 \pm 1.0^{\circ} \mathrm{C}$ on a 10:14 h light:dark photoperiod. Illumination was provided by two $30 \mathrm{~W}$ Vita-Lite ${ }^{\circledR}$ (Duro-Test Canada) fluorescent tubes placed $1.5 \mathrm{~m}$ from the eggs. The spectral output of these lamps includes some longwave ultraviolet-A (320 to $400 \mathrm{~nm}=\mathrm{UV}-\mathrm{A}$ ); photorepair mechanisms should have been active under this light regime (Mitchell et al. 1993, Mitani et al.
1996). The PAR (400 to $700 \mathrm{~nm}$ ) output of these lamps, at the position where the eggs were incubated, was $0.03 \mathrm{~W} \mathrm{~m}^{-2}$.

At $6.0^{\circ} \mathrm{C}, 85$ to $95 \%$ of Calanus finmarchicus eggs would normally hatch after $72 \mathrm{~h}$ (McLaren et al. 1988). Thus, $3 \mathrm{~d}$ after UV irradiation, each Petri dish was examined under a dissecting microscope, and its content categorized as eggs, live (viable) nauplii, dead nauplii, or living but clearly deformed (missing appendage) non-viable nauplii. To distinguish between live and dead nauplii, animals were probed with a needle. Nauplii that exhibited an escape reaction were classified as alive. In some cases, the total number of items in a Petri plate did not add up to 50. Although we could not determine the reason for this, the small eggs $(150 \mu \mathrm{m})$ were probably lost during the manipulations both at the beginning and at the end of the experiment. There was no systematic pattern of egg loss amongst treatments, and the loss was typically $<10 \%$. Egg loss was not a result of their having died and quickly disintegrated, since in test trials it took longer than 2 to $3 \mathrm{~d}$ for dead eggs (killed by heat shock) to disintegrate.

The number of live nauplii, as a proportion of the total number of items recovered from the Petri plates, was chosen to test the effect of spectral exposure, dose and dose rate on the viability of eggs. To test the null hypothesis that there was no effect of either spectral exposure treatment or dose rate on offspring viability (expressed as the proportion of live nauplii), 2-way ANOVAs were applied to arcsin-square-root-transformed data from the dose experiments. Significant differences were localized by pairwise multiple comparisons (Bonferroni $t$-test).

Results. The proportion of live nauplii in the UVexposed spectral treatments was discernibly reduced in the medium and high dose groups relative to the low dose group (Table 2, Fig. 2).

Spectral exposure had a statistically discernible effect on the proportion of live nauplii produced from

Table 1. Summary of the dose rates (i.e. irradiances), exposure times and doses of ultraviolet (290-350 nm) radiation delivered to Calanus finmarchicus embryos during the experiments testing reciprocity. Doses are presented as $\mathrm{kJ} \mathrm{m}^{-2}$, dose rates as $\mathrm{W} \mathrm{m}^{-2}$. SS: solar simulator

\begin{tabular}{|lccccc|}
\hline SS output $(\mathrm{W})$ & $\begin{array}{c}\text { Mean dose rate } \\
( \pm \text { SD })\end{array}$ & $\begin{array}{c}\text { Designation of } \\
\text { dose rate }\end{array}$ & $\begin{array}{c}\text { Exposure } \\
\text { time }(\mathrm{s})\end{array}$ & $\begin{array}{c}\text { Mean dose } \\
( \pm \text { SD })\end{array}$ & $\begin{array}{c}\text { Designation } \\
\text { of dose }\end{array}$ \\
\hline 600 & $10.675(0.930)$ & Low & 180 & $1.922(0.167)$ & Low \\
800 & $17.184(1.497)$ & Medium & 120 & $2.062(0.180)$ & Low \\
1000 & $22.609(1.969)$ & High & 90 & $2.035(0.177)$ & Low \\
600 & $10.675(0.930)$ & Low & 276 & $2.946(0.257)$ & Medium \\
800 & $17.184(1.497)$ & Medium & 192 & $3.299(0.287)$ & Medium \\
1000 & $22.609(1.969)$ & Low & 150 & $3.391(0.295)$ & Medium \\
600 & $10.675(0.930)$ & Medium & 552 & $5.893(0.513)$ & High \\
800 & $17.184(1.497)$ & High & 390 & $6.702(0.584)$ & High \\
1000 & $22.609(1.969)$ & & & $6.783(0.591)$ & High \\
\hline
\end{tabular}


Table 2. Summary of the 2-way ANOVAs performed on the viability of Calanus finmarchicus eggs exposed to UV radiation at different doses and dose rates (i.e. irradiances). Within each dose, viability was tested against spectral exposure treatment and dose rate

\begin{tabular}{|llcccrr|}
\hline Dose & Effect & df & SS & MS & $F$ & p \\
\hline Low & Spectral exposure & 3 & 0.275 & 0.092 & 4.795 & 0.005 \\
& Dose rate & 2 & 0.037 & 0.018 & 0.964 & 0.388 \\
\multirow{2}{*}{ Medium } & Spectral exposure & 3 & 1.788 & 0.596 & 20.194 & $<0.001$ \\
& Dose rate & 2 & 0.033 & 0.017 & 0.564 & 0.574 \\
High & Spectral exposure & 3 & 0.974 & 0.325 & 19.409 & $<0.001$ \\
& Dose rate & 2 & 0.060 & 0.030 & 1.790 & 0.178 \\
& & & & & & \\
\hline
\end{tabular}

irradiated embryos (Table 2, Fig. 2). In the medium and high dose exposures, only the difference between $>305 \mathrm{~nm}$ exposure and the dark control group was always significant (Bonferroni $t$-test, $\mathrm{p}=0.05$; Fig. 2).

Dose rate had no statistically discernible effect on the proportion of live Calanus finmarchicus nauplii: this was consistent amongst all spectral exposures and doses (Table 2, Fig. 2).

The range of modelled daily UV (290 to $350 \mathrm{~nm}$ ) exposures, which Calanus finmarchicus embryos were subjected to, varied from $\sim 0$ to $127 \mathrm{~kJ} \mathrm{~m}^{-2} \mathrm{~d}^{-1}$ (Table 3). Within a single model run (i.e. any $1 \mathrm{~d}$ simulation which uses the same environmental parameters) there was also a significant variation in exposure amongst the embryo assemblage. For instance, using diffuse attenuation coefficients from the estuary of the St. Lawrence River, under cloudy conditions, $10 \mathrm{~m} \mathrm{~s}^{-1}$ winds, and a $10 \mathrm{~m}$ mixed layer, embryo exposures ranged from 0.0003 to $17.9 \mathrm{~kJ} \mathrm{~m}^{-2} \mathrm{~d}^{-1}$. A comparison of Tables 1 and 3 demonstrates the overlap of doses administered in the reciprocity experiments with those to which $C$. finmarchicus embryos could be exposed in their natural environment over the course of a day.

The modelled maximum UV (290 to $350 \mathrm{~nm}$ ) exposure rates to which 3 representative Calanus finmarchicus embryos were exposed ranged from approximately 2 to $18 \mathrm{~W} \mathrm{~m}^{-2}$ (Fig. 3). Modelled daily total exposures for these embryos were 106 (clear sky), 5.5 (cloudy sky) and 0.4 (cloudy sky) $\mathrm{W} \mathrm{m}^{-2} \mathrm{~d}^{-1}$, and the duration of embryo exposures to dose rates greater than $2 \mathrm{~W} \mathrm{~m}^{-2}$ during the course of a day were 284,15 and 1 min (Fig. 3A-C, respectively). A comparison of these values with those in Table 1 demonstrates that the dose rates and exposure times used in the reciprocity experiments overlap with those to which $C$. finmarchicus embryos could be exposed in their natural environment over the course of a day.

Discussion. In general, the trend in dose-dependent UV-induced mortality resulting from these exposures is consistent with that reported from previous experiments with Calanus finmarchicus (Kouwenberg et al. 1999b, Alonso Rodriguez et al. 2000) and with those for other species of crustacean zooplankton (e.g. Tartarotti et al. 2000, Williamson et al. 2001). The viability of C. finmarchicus embryos is negatively affected by even brief exposures to UV radiation (e.g. only 2.5 to $4.6 \mathrm{~min}$ in the medium dose experiment; Table 1, Fig. 2). However, under these experimental conditions, dose rate had no discernible effect on the proportion of live C. finmarchicus nauplii recovered from eggs exposed to 3 different UV doses: reciprocity held. The radiative conditions used in this test of reciprocity were ecologically relevant (Table 3, Fig. 3) and fall within the range of those delivered in the experiments used to derive the BWF for C. finmarchicus (Kouwenberg et al. 1999b). Further, reciprocity held despite the eggs having been given the opportunity to photo-repair.
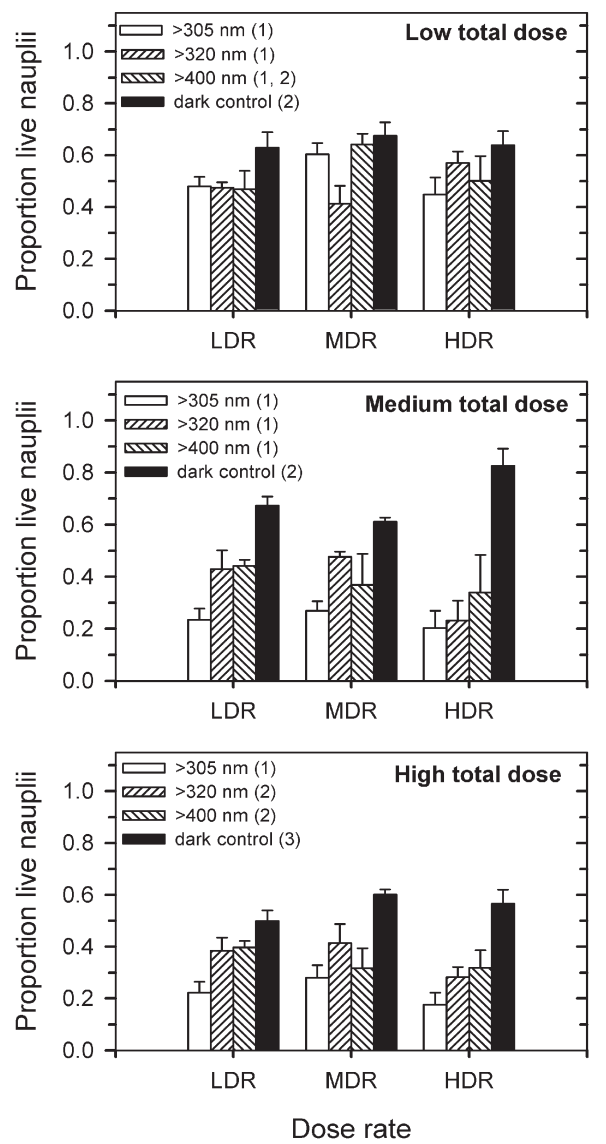

Fig. 2. Calanus finmarchicus. Proportion of live nauplii recovered from eggs exposed to 3 different UV doses at 3 different dose rates. The mean values are topped by standard error bars. $\mathrm{LDR}=$ low dose rate, $\mathrm{MDR}=$ medium dose rate $; \mathrm{HDR}=$ high dose rate. Numbers in parentheses next to the spectral exposure treatments denote statistical discernability: exposure treatments with the same number are not different $(p=0.05)$ 
Thus, the BWF of Kouwenberg et al. (1999b) can reasonably be applied to quantify the wavelength-specific impact of UV on the eggs of this species.

The principle of reciprocity has not been rigorously evaluated for many species, and, when it has, the results have been inconsistent-for organisms at all taxonomic levels, reciprocity sometimes holds and sometimes does not. The status of the issue for phytoplankton will not be covered here, as it has been reviewed a number of times (e.g. Smith \& Cullen 1995, Heraud \& Beardall 2000).
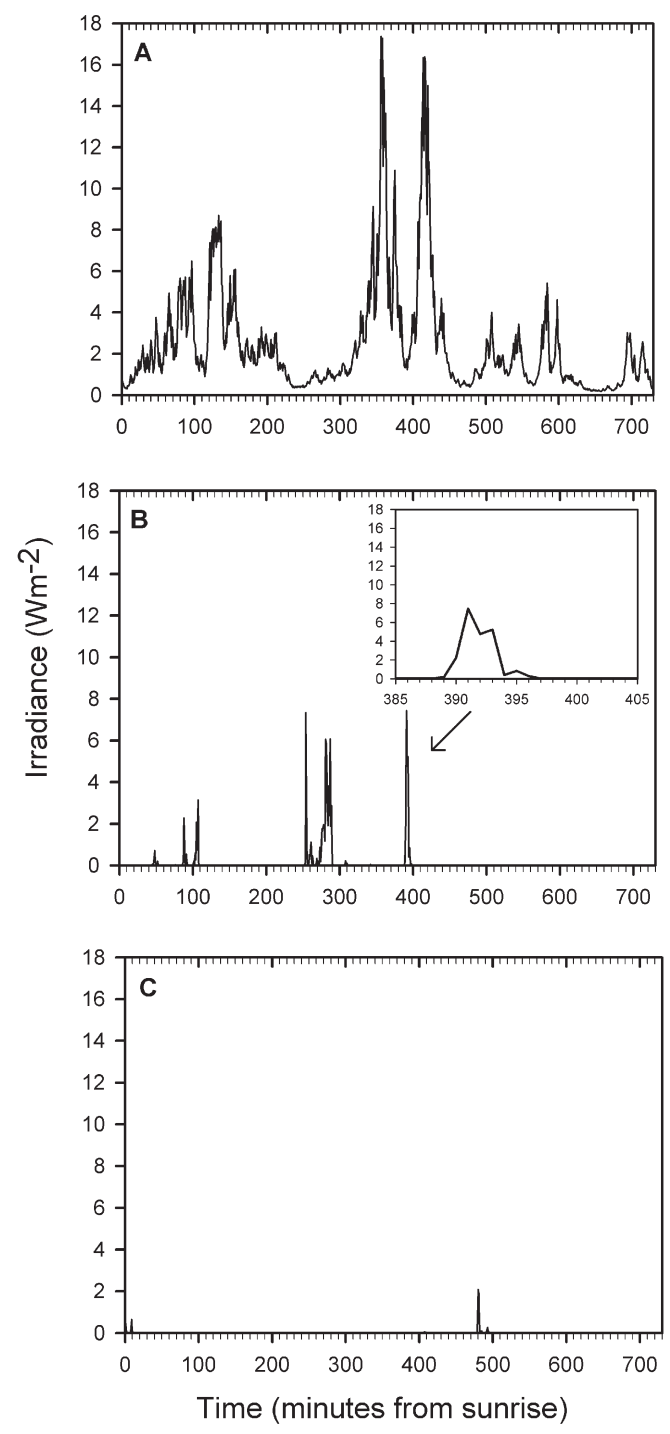

Fig. 3. Modelled UV radiation dose rates $(290-350 \mathrm{~nm})$ to which Calanus finmarchicus embryos are exposed over the course of a day in a water column with a $10 \mathrm{~m}$ mixed layer. (A) Under clear skies and Gulf of St. Lawrence diffuse attenuation coefficients (clear water). (B) and (C) are different embryos, exposed under the same conditions, cloudy skies and diffuse attenuation coefficients from more UV-opaque estuary water
Table 3. Summary of modelled daily UV (290-350 nm) exposures of Calanus finmarchicus embryos. Exposure ranges were calculated for diffuse attenuation coefficients of water columns in the Gulf $\left(1.1-0.3 \mathrm{~m}^{-1}\right)$ and estuary $\left(5.9-3.0 \mathrm{~m}^{-1}\right)$ of the St. Lawrence river, Quebec, Canada, for mixed layer depths of $10-50 \mathrm{~m}$, and surface wind speeds of $0-10 \mathrm{~m} \mathrm{~s}^{-1}$. For all model simulations, embryos were initially distributed in the top $5 \mathrm{~m}$ of the water column and assigned a sinking rate of $32 \mathrm{~m} \mathrm{~d}^{-1}$ (Marshall \& Orr 1953). All simulations were performed under extant ambient atmospheric ozone levels. For details of the model, see Kuhn et al. (2000)

\begin{tabular}{|lcc|}
\hline $\begin{array}{l}\text { Atmospheric } \\
\text { conditions }\end{array}$ & $\begin{array}{c}\text { Diffuse attenuation coefficient } \\
\left(\mathrm{m}^{-1}\right)(290-350 \mathrm{~nm})\end{array}$ & $\begin{array}{c}\text { Exposure } \\
\left(\mathrm{kJ} \mathrm{m}^{-2} \mathrm{~d}^{-1}\right)\end{array}$ \\
\hline Clear sky & $1.1-0.3$ & $0.0^{\mathrm{a}-37.3}$ \\
Cloudy sky & $5.9-3.0$ & $2.1-127.0$ \\
& $1.1-0.3$ & $0.0^{\mathrm{a}}-17.9$ \\
${ }^{a}$ Values were $\ll 0.1 \mathrm{~J} \mathrm{~m}^{-2} \mathrm{~d}^{-1}$ & $0.4-79.0$ \\
\hline
\end{tabular}

In marine crustaceans, reciprocity failed to hold for larvae of the shrimp Pandalus platyceros (Damkaer et al. 1981) and for adults of the euphausid Thysanoessa raschii (Damkaer \& Dey 1983). Neither does reciprocity hold for freshwater species such as the cladocerans Daphnia spp. (Siebeck \& Böhm 1994, Grad et al. 2001) and Ceriodaphnia dubia (Zagarese et al. 1998a), the nymphs of the mayfly Diphetor hageni, or the chironomid Corynomeura taris (McNamara \& Hill 1999). However, reciprocity holds for the freshwater copepod Boeckella gracilipes (Zagarese et al. 1997, 1998a,b) and the freshwater rotifer Asplanchna girodi (Grad et al. 2001), both species that apparently lack a strong capacity to photo-repair UV-induced cellular damage. Unfortunately, the photo-repair capacity of Calanus finmarchicus has not been investigated. In experiments analogous to those reported here, reciprocity held for embryonic Atlantic cod Gadus morhua, despite the fact that the eggs were incubated under fluorescent lamps in-between UV exposures (i.e. they were allowed to photorepair) (Kouwenberg et al. 1999a). For northern anchovy Engraulis mordax larvae, and under relatively broad dose/dose rate exposures, reciprocity did not hold (Hunter et al. 1981, 1982). Why reciprocity holds for Atlantic cod but not for northern anchovy is unknown. However, one possibility is the difference in the relative duration of intense UV-B exposures versus the time for repair. When the rate of repair dominates the rate of damage, reciprocity fails (see also Grad et al. 2001, Williamson et al. 2001). When damage dominates, repair processes will not significantly compromise reciprocity. In evaluations of reciprocity, it is important to acknowledge that experiments conducted on different time scales may yield significantly different results (Grad et al. 2001, Williamson et al. 2001). 
In summary: the few studies examining reciprocity in crustacean zooplankton and ichthyoplankton have yielded contradictory results. In general, it appears that reciprocity holds mainly for organisms without a strong capacity for photo-repair. However, the issue of dose versus dose-rate effects on marine organisms requires further investigation, at a broad range of dose and dose rates and for different exposure durations (similar to the range of modelled exposure scenarios presented above), preferably under natural sunlight.

Acknowledgements. Marise Bélanger and Pierre Joly assisted with the experiments, and Richard Davis with the simulation modelling. We are grateful to John Cullen for his advice and support throughout all of our work on UV radiation impacts. The experiments reported here were financed by the Department of Fisheries and Oceans Canada, the St. Lawrence Vision 2000 Program, and the Natural Sciences and Engineering Research Council of Canada. H.I.B.'s current work on UV radiation impacts (including the preparation of this contribution) is supported by funds from the Norwegian Institute of Marine Research and by the Research Council of Norway (Project 140472/130).

\section{LITERATURE CITED}

Alonso Rodriguez C, Browman HI, Runge JA, St-Pierre JF (2000) Impact of solar ultraviolet radiation on hatching of a marine copepod, Calanus finmarchicus. Mar Ecol Prog Ser 193:85-93

Ban S, Burns C, Castel J, Chaudron Y and 19 others (1997) The paradox of diatom-copepod interactions. Mar Ecol Prog Ser 157:287-293

Browman HI (2003) Assessing the impacts of solar ultraviolet radiation on the early life stages of crustacean zooplankton and ichthyoplankton in marine coastal systems. Estuaries 26(1):30-39

Cullen JJ, Neale PJ (1997) Biological weighting functions for describing the effects of ultraviolet radiation on aquatic systems. In: Häder DP (ed) The effects of ozone depletion on aquatic ecosystems. RG Landes, Austin, TX, p 97-118

Damkaer DM, Dey DB (1983) UV damage and photoreactivation potentials of larval shrimp, Pandalus platyceros, and adult euphausiids, Thysanoessa raschii. Oecologia 60: 169-175

Damkaer DM, Dey DB, Heron GA (1981) Dose/dose-rate responses of shrimp larvae to UV-B radiation. Oecologia 48:178-182

DeGruijl FR, Sterenborg HJCM, Slaper H, van der Leun JC (1986) Dose and dose-rate responses to UV-B radiation: implications for reciprocity. In: Worrest RC, Caldwell MM (eds) Stratospheric ozone reduction, solar ultraviolet radiation and plant life. Springer-Verlag, Berlin, p 119-126

Grad G, Williamson CE, Karapelou DM (2001) Zooplankton survival and reproduction responses to damaging UV radiation: a test of reciprocity and photoenzymatic repair. Limnol Oceanogr 46:584-591

Heraud P, Beardall J (2000) Changes in chlorophyll fluorescence during exposure of Dunaliella tertiolecta to UV radiation indicate a dynamic interaction between damage and repair processes. Photosynth Res 63:123-134

Hunter JR, Kaupp SE, Taylor JH (1981) Effects of solar and artificial ultraviolet-B radiation on larval northen anchovy, Engraulis mordax. Photochem Photobiol 34:477-486
Hunter JR, Kaupp SE, Taylor JH (1982) Assessment of effects of UV radiation on marine fish larvae. In: Calkins J (ed) The role of solar ultraviolet radiation in marine ecosystems. Plenum Press, New York, p 459-493

Kouwenberg JHM, Browman HI, Cullen JJ, Davis RF, St-Pierre JF, Runge JA (1999a) Biological weighting of ultraviolet (280-400 nm) induced mortality in marine zooplankton and fish. I. Atlantic cod (Gadus morhua L.) eggs. Mar Biol 134:269-284

Kouwenberg JHM, Browman HI, Runge JA, Cullen JJ, Davis RF, St-Pierre JF (1999b) Biological weighting of ultraviolet $(280-400 \mathrm{~nm})$ induced mortality in marine zooplankton and fish. II. Calanus finmarchicus eggs. Mar Biol 134:285-293

Kuhn P, Browman HI, St-Pierre JF, McArthur B (1999) Penetration of ultraviolet radiation in the waters of the estuary and Gulf of St. Lawrence. Limnol Oceanogr 44:710-716

Kuhn P, Browman HI, Davis RF, Cullen JJ, McArthur B (2000) Modelling the effects of ultraviolet radiation on embryos of Calanus finmarchicus and Atlantic cod (Gadus morhua) in a mixing environment. Limnol Oceanogr 45:1797-1806

Marshall SM, Orr AP (1953) Calanus finmarchicus egg production and egg development in Tromsø Sound in spring. Acta Borealia Sci 5:1-21

McLaren IA, Sevigny JM, Corckett CJ (1988) Body sizes development rates and genome sizes among Calanus species. Hydrobiologia 167/168:275-284

McNamara AE, Hill WR (1999) Effects of UV-B dose and irradiance: comparison among grazers. J N Am Benthol Soc 18:370-380

Mitani H, Uchida N, Shima A (1996) Induction of cyclobutane pyrimidine dimer photolyase in cultured fish cells by UVA and blue light. Photochem Photobiol 64:943-948

Mitchell DL, Travis Scoggins J, Morizot DC (1993) DNA repair in the variable platyfish (Xiphophorus variatus) irradiated in vivo with ultraviolet B light. Photochem Photobiol 58:455-459

Neale PJ, Fritz JJ, Davis RF (2001) Effects of UV on photosynthesis of Antarctic phytoplankton: models and their application to coastal and pelagic assemblages. Rev Chilena Hist Natl 74:283-292

Runge JA, Plourde S (1996) Fecundity characteristics of Calanus finmarchicus in coastal waters of eastern Canada. Ophelia 44:171-187

Siebeck O, Böhm U (1994) Challenges for an appraisal of UV$B$ effects upon crustaceans under natural radiation conditions with a non-migrating (Daphnia pulex obtusa) and a migrating cladoceran (Daphnia galeata). Arch Hydrobiol Beih Ergeb Limnol 43:197-206

Smith RC, Cullen JJ (1995) Effects of UV radiation on phytoplankton. Am Geophys Union (Suppl):1211-1223

Tartarotti B, Cravero W, Zagarese HE (2000) Biological weighting function for the mortality of Boeckella gracilipes (Copepoda, Crustacea) derived from experiments with natural solar radiation. Photochem Photobiol 72:314-319

Williamson CE, Neale PJ, Grad G, De Lange HJ, Hargreaves BR (2001) Beneficial and detrimental effects of UV on aquatic organisms: implications of spectral variation. Ecol Appl 11:1843-1857

Zagarese HE, Feldman M, Williamson CE (1997) UV-B-induced damage and photoreactivation in three species of Boeckella (Copepoda, Calanoida). J Plankton Res 19:357-367

Zagarese HE, Tartarotti B, Cravero W, Gonzalez P (1998a) UV damage in shallow lakes: the implications of water mixing. J Plankton Res 20:1423-1433

Zagarese HE, Cravero W, Gonzalez P, Pedrozo F (1998b) Copepod mortality induced by fluctuating levels of natural solar radiation simulating vertical water mixing. Limnol Oceanogr 43:169-174 